\title{
ACTIVIDAD ANTIFÚNGICA DE PESTICIDAS BIOLÓGICOS, BOTÁNICOS Y QUÍMICOS SOBRE EL AGENTE CAUSAL DE LA MARCHITEZ VASCULAR DEL JITOMATE
}

\author{
ANTIFUNGAL ACTIVITY OF BIOLOGICAL, BOTANICAL AND CHEMICAL \\ PESTICIDES ON THE CAUSAL AGENT OF WILD DISEASES OF TOMATO
}

\author{
Sergio Ayvar-Serna ${ }^{1}$, José Francisco Díaz-Nájera', Mateo Vargas-Hernández²*, Guillermo

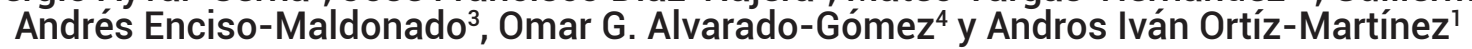

\begin{abstract}
'Colegio Superior Agropecuario del Estado de Guerrero, Iguala de la Independencia, Guerrero, México. ²Universidad Autónoma Chapingo, Departamento de Suelos, Chapingo, Edo. de México. ${ }^{3}$ Centro de Desarrollo e Innovación Tecnológica, Hohenau, Departamento de Itapúa, Paraguay. ${ }^{4}$ Universidad Autónoma de Nuevo León, Facultad de Agronomía, San Nicolás de los Garza, Nuevo León, México.

*Autor de correspondencia (vargas_mateo@hotmail.com)
\end{abstract}

\section{RESUMEN}

La marchitez vascular del jitomate (Solanum lycopersicum L.) es una de las enfermedades más importantes que afecta la producción alrededor del mundo. El control biológico ha emergido como una de las alternativas más promisorias al uso de fungicidas químicos. El objetivo de esta investigación fue diagnosticar el agente causal de la enfermedad y probar la efectividad in vitro de compuestos comerciales biológicos, botánicos y químicos contra el patógeno. Se realizó el aislamiento monospórico del hongo, se extrajo y amplificó el ADN de las regiones ITS1 e ITS2 del ADN ribosomal y del fragmento del gen del factor de elongación de la traducción (TEF-1a). Las secuencias se compararon con las reportadas en la base del NCBI mediante el software BLAST-N. En el Ensayo I se evaluó la efectividad contra el patógeno de los metabolitos difusibles en PDA de las cepas nativas Trichoderma sp. y $T$. asperellum, además de las comerciales $T$. virens G-41 y $T$. harzianum. En el Ensayo II se evaluó in vitro la fungitoxicidad de pesticidas químicos y botánicos contra el hongo. Ambos ensayos se realizaron usando un diseño completamente al azar, con cuatro repeticiones. Se realizó el ANOVA y la prueba de Tukey $(P=0.05)$. Se identificó al agente causal como Fusarium solani. Los controladores Trichoderma sp. y T. virens G-41 presentaron la máxima efectividad, con 77.19 y $77.81 \%$ de reducción del crecimiento micelial del hongo. Zineb, extractos de canela, neem y ajo redujeron entre 30 y $43.75 \%$ el crecimiento del patógeno. Comparativamente, el oxicloruro de cobre, captan, carbendazim, mancozeb y benomilo controlaron $100 \%$ a F. solani. Se concluye que los pesticidas biológicos y botánicos actúan como fungistáticos contra $F$. solani y los fungicidas de contacto son efectivos para suprimir el crecimiento del patógeno.

Palabras clave: Fusarium solani, Solanum lycopersicum L., control biológico, extractos vegetales, fungicidas.

\section{SUMMARY}

The vascular wilt of tomato (Solanum lycopersicum L.) is one of the most important diseases that affect production around the world. Biological control has emerged as one of the most promising alternatives to the use of chemical fungicides. The aim of this research was to diagnose the causative agent of the disease and to test the in vitro effectiveness of commercial biological, botanical and chemical compounds against the pathogen. Monosporic isolation of the fungus was performed, the DNA was extracted and amplified from the ITS1 and ITS2 regions of the ribosomal DNA and from the gene fragment of the translation elongation factor (TEF-1a). The sequences were compared with those reported in the NCBI database using BLAST-N software. In Trial I was tested the effectiveness against the pathogen of diffusible metabolites in PDA of the native Trichoderma sp. and $T$. asperellum, in addition to the commercial $T$. virens G-41 and T. harzianum. In Test II, the fungitoxicity of chemical and botanical pesticides against the fungus was tested in vitro. Both trials were conducted using a completely randomized design with four repetitions. The ANOVA and the Tukey test $(P=0.05)$ were performed. The causative agent was identified as Fusarium solani. Trichoderma sp. and T. virens G-41 caused the highest percentage of fungal mycelial growth inhibition, with 77.19 and $77.81 \%$. Zineb, extracts of cinnamon, neem and garlic reduced pathogen growth by 30 to $43.75 \%$. Comparatively, cooper oxiclorure, captan, carbendazim, mancozeb and benomilo had a $100 \%$ control over $F$. solani. It is concluded that biological and botanical pesticides act as fungistatics against F. solani and contact fungicides are effective to suppress the growth of the pathogen.

Index words: Fusarium solani, Solanum lycopersicum, biological control, fungicides, plant extracts.

\section{INTRODUCCIÓN}

Solanum lycopersicum L. es uno de los cultivos hortícolas de mayor importancia económica en la mayoría de las regiones agrícolas del mundo (Renna et al., 2018). El consumo de fruto ofrece beneficios para la nutrición y la salud, debido a que tiene alto contenido de potasio, antioxidantes (vitamina A, ácido ascórbico, licopeno y tocoferoles) (Naranjo et al., 2016). Además, es materia prima para la agroindustria y presenta propiedades benéficas para disminuir el riesgo de cáncer, osteoporosis y enfermedades cardiovasculares (Bhowmik et al., 2012; Fiedor y Burda, 2014). El cultivo es atacado por especies de Fusarium que infectan el tejido vascular y causan la marchitez y muerte de la planta (Malandrakis et al., 2018; Portal et al., 2018). El patógeno Fusarium solani (Martius) Sacc. [teleomorfo: Haematonectria haematococca (Berk. y Broome) Samuels y Rossman], puede provocar infección en cualquier etapa fenológica del cultivo y afecta significativamente la productividad y rentabilidad del jitomate (Rashid et al., 2021). Los intentos por reducir o sustituir el uso de fungicidas químicos para controlar 
la enfermedad han hecho necesario el desarrollo de alternativas basadas en microorganismos rizógenos y fitoextractos, los cuales son naturales y no representan una amenaza para la salud humana y el ambiente (Osuna-Canizalez et al., 2012). Diferentes especies de Trichoderma (Hypocreales) se han evaluado como agentes biocontroladores de hongos fitopatógenos de la raíz (Michel-Aceves et al., 2019), ya que actúan mediante mecanismos de competencia por nutrientes y espacio, metabolitos secundarios antifúngicos, micoparasitismo (Silva et al., 2019; Romero-Rosales et al., 2021) e inducción de resistencia, por lo que pueden proteger y promover el desarrollo integral de las plantas (Andrade-Hoyos et al., 2020; Rashid et al., 2021). Se ha reportado que Trichoderma harzianum T-H4 inhibió $63.6 \%$ el crecimiento del micelio de Fusarium sp. y presentó antagonismo clase III de la escala de Bell (Morales et al., 2020). De la misma manera, Nagendran et al. (2016) obtuvieron promedios mayores de $50 \%$ de inhibición sobre el crecimiento micelial de F. solani, utilizando 15 aislamientos de Trichoderma spp. Por otra parte, se ha incrementado el uso de fungicidas botánicos como una alternativa prometedora a los plaguicidas químicos en la agricultura y la producción de alimentos orgánicos (Zaker, 2016; Dan et al., 2021). Algunos extractos vegetales se están utilizando a nivel mundial como pesticidas verdes, aplicados en la semilla, al follaje y suelo (Varma y Saran, 2019). En la producción orgánica cada vez es más frecuente la utilización de extractos obtenidos de ajo (Allium sativum L.), canela (Cinnammomum zeylanicum L.), neem (Azadirachta indica A. Juss), piretro (Tanacetum cinerariifolium), cúrcuma (Curcuma longa), romero (Rosmarinus officinalis), jengibre (Zingiber officinale) y tomillo (Thymus vulgaris) (Lengai et al., 2020). Estas plantas poseen metabolitos secundarios bioactivos como esteroides, alcaloides, taninos, terpenos, fenoles, flavonoides y resinas con propiedades antifúngicas, antibacterianas, antioxidantes o insecticidas (Ahmad et al., 2017; Lengai et al., 2020) y han resultado valiosas como fuente de fungicidas botánicos.

Actualmente, debido al creciente interés de utilizar agentes de control biológico y botánicos para reducir, alternar o reemplazar el uso excesivo de pesticidas químicos (Damalas, 2016) es necesario continuar investigando el potencial que tienen algunos de estos productos comerciales para el manejo específico de $F$. solani, como alternativa a los fungicidas sintéticos (Lengai et al., 2020). El objetivo de la presente investigación fue identificar al agente causal de la marchitez vascular en jitomate y comparar la efectividad biológica in vitro de compuestos orgánicos, químicos y biológicos, para seleccionar los tratamientos con mayor potencial para inhibir o suprimir al patógeno.

\section{MATERIALES Y MÉTODOS}

\section{Localización y muestreo de plantas enfermas}

La investigación se realizó en el Laboratorio de Fitopatología del Centro de Estudios Profesionales del Colegio Superior Agropecuario del Estado de Guerrero (CEP-CSAEGRO), ubicado en el kilómetro 14.5 de la carretera Iguala-Cocula (18 14' 00" LO y $99^{\circ} 40^{\prime} 00^{\prime \prime}$ LN), a $640 \mathrm{~m}$ de altitud. En esta región predomina un clima tropical seco Awo(w)(i)g. El muestreo de plantas se realizó en una parcela comercial (1 ha) de jitomate de la variedad Rio Grande de dos meses de edad, con alrededor de $12 \%$ de plantas enfermas. Mediante recorridos en el cultivo se localizaron plantas con síntomas de enanismo, clorosis y marchitez del follaje y se colectaron al azar raíces de 10 plantas enfermas.

\section{Aislamiento y purificación del hongo}

Se seleccionaron raíces secundarias del total de la muestra, se lavaron con agua y jabón y se cortaron segmentos de $5 \mathrm{~mm}$ de largo, que contenían tejido sano y enfermo. Posteriormente, los segmentos se desinfectaron por inmersión en hipoclorito de sodio al $1 \%$ por 30 a 60 segundos y se enjuagaron con agua destilada estéril. Cinco segmentos se depositaron sobre dos portaobjetos en cámara húmeda preparada en una caja Petri (Keyworth, 1951). Se hicieron cinco repeticiones y se incubaron por cinco días en el laboratorio de Fitopatología a temperatura ambiente de $28 \pm 1{ }^{\circ} \mathrm{C}$, fotoperiodo natural luz/oscuridad ( $12 \mathrm{~h} / 12 \mathrm{~h}$ ) y $45 \%$ de humedad relativa.

De los segmentos de tejido colonizados con micelio y conidios se realizó el estriado de conidios sobre medio de cultivo agua-agar $(A-A)$ y después de $24 \mathrm{~h}$ se transfirieron conidios individuales a nuevo A-A en caja Petri para obtener 10 cepas monospóricas del hongo (Leslie y Summerell, 2006), las cuales se incubaron por 3 días y se preservaron en $\mathrm{A}$-A en tubo de ensayo a $4-5^{\circ} \mathrm{C}$.

\section{Identificación morfológica y molecular del agente causal de la pudrición radical y marchitez en jitomate}

Se utilizaron colonias de cinco días de incubación en medio de cultivo papa-dextrosa agar (PDA), a temperatura ambiente $\left(28 \pm 2{ }^{\circ} \mathrm{C}\right)$ y fotoperiodo natural $(12 \mathrm{~h} / 12$ h). Se hicieron preparaciones en lactofenol claro del micelio y esporas del hongo, tomando en cuenta las características morfológicas de los micro y macronidios, fiálides y presencia de clamidosporas observadas en el microscopio (objetivos 40X y 100X) y con las claves de Leslie y Summerell (2006) y Watanabe (2010) se realizó la identificación de los aislados monospóricos del hongo. 
Para la identificación molecular se utilizaron colonias fungosas cultivadas por siete días en PDA; con estas mismas colonias se realizó la extracción de ADN, siguiendo el procedimiento comercial del DNAzol ES (Molecular Research Center). Se realizó la amplificación por PCR de las regiones internas transcritas ITS1 e ITS2 del ADN ribosomal y del fragmento del gen del factor de elongación de la traducción (TEF-1a), utilizando el par de oligonucleótidos de secuencia ITS1 (5'-TCCGTAGGTGAACCTGCGG-3') e ITS4 (5'-TCCTCCGCTTATTGATATGC-3') (White et al., 1990) y EF-1 (5'-GTTAAGAGGCGCGGTGTCGGTGTG-3') y EF-2 (5'-GGAAGTACCAGTGATCATGTT-3') (Hsuan et al., 2011). Se obtuvieron amplicones de 500 pb para ITS y 700 pb aproximadamente para TEF-1a. Las secuencias fueron comparadas con las secuencias reportadas en la base de datos del banco de genes del NCBI (National Center for Biotechnology Information) mediante el software BLAST-N (https://blast.ncbi.nlm.nih.gov/Blast.cgi) para la identificación del hongo.

\section{Postulados de Koch}

Se utilizaron 22 plantas de la variedad Río Grande, cultivadas previamente en almácigo por 30 días en arena de río estéril en vasos de poliestireno No 12. La multiplicación de inóculo del hongo se realizó en glumas de avena esterilizadas en matraces Erlenmeyer de 500 $\mathrm{mL}$, en los cuales se inocularon por separado discos de A-A $(\varnothing=5 \mathrm{~mm})$ de tres aislamientos monospóricos del hongo, de 10 días de incubación previa en A-A. Se hicieron dos repeticiones y se utilizó un testigo de cada aislado, lo cuales fueron incubados a $\pm 28{ }^{\circ} \mathrm{C}$ por 15 días, hasta que el hongo colonizó las glumas. Previo a la inoculación se preparó sustrato infestado, mezclando $30 \mathrm{~g}$ de arena esterilizada con $30 \mathrm{~g}$ de glumas + el hongo $\left(3.5 \times 10^{8}\right.$ ufc $\left.\mathrm{g}^{-1}\right)$, mezcla utilizada para llenar vasos de poliestireno $\left(\mathrm{N}^{\circ}\right.$ 12) en los que se trasplantó la planta sana de jitomate de 30 días de cultivo en el almácigo. De cada cepa monospórica se hicieron cinco repeticiones y se utilizaron dos plantas como control. Las plantas se mantuvieron en invernadero y se inspeccionaron en forma continua hasta la manifestación de síntomas de marchitez. Se realizó el reaislamiento del hongo para finalizar los postulados de Koch (Agrios, 2005).

\section{Ensayo I. Efecto de Trichoderma spp. contra el hongo fitopatógeno}

El primer ensayo consistió en evaluar la antibiosis de los metabolitos secundarios de Trichoderma, difusibles en medio de cultivo papa-dextrosa-agar (PDA), contra el hongo patógeno; para lo cual se utilizaron los siguientes tratamientos: T1: Testigo, T2: Trichoderma sp. (Cepa nativa de Iguala), T3: Trichoderma asperellum (Cepa nativa de Cocula), T4: Trichoderma virens G-41 (PHC ${ }^{\circledR}$ ROOTMATE ${ }^{\circledR}$, T5: Trichoderma harzianum $\left(\right.$ LABRADOR $\left.^{\circledR}\right)$. Los tratamientos se distribuyeron en un diseño completamente al azar con cuatro repeticiones. Cada una de las 20 unidades experimentales fue una caja Petri con $20 \mathrm{~mL}$ de PDA mezclado con los metabolitos secundarios difusibles producidos por Trichoderma spp. Las cepas comerciales de este hongo se mantuvieron en PDA a $4-5^{\circ} \mathrm{C}$ en el laboratorio de Fitopatología.

Las cepas de Trichoderma nativas de Iguala y Cocula se obtuvieron en cultivo monospórico (Waller et al., 2002), mediante la técnica de dilución en placa, las cuales se identificaron morfológicamente (Watanabe, 2010) y se transfirieron a PDA en tubos de ensayo para la preservación del hongo. Todas las cepas de Trichoderma se reactivaron transfiriéndolas del PDA en tubo de ensayo a PDA en cajas Petri, dos días antes de iniciar el bioensayo. Para medir la efectividad de metabolitos secundarios extracelulares difusibles en el medio de cultivo producidos por las cepas de Trichoderma spp. se utilizó la técnica de la membrana de celofán (Hoda et al., 2016), en un diseño experimental completamente al azar con cinco repeticiones. La unidad experimental fue la caja Petri con $20 \mathrm{~mL}$ de PDA, que contenía los metabolitos secretados por las cepas de Trichoderma. En el centro de la caja se sembró el hongo patógeno de ocho días de incubación en PDA. Las cajas se incubaron $\mathrm{a} \pm 28^{\circ} \mathrm{C}$ y fotoperiodo natural en el laboratorio. Diariamente se midió el diámetro de la colonia del hongo durante 144 horas (seis días) y con estos datos se obtuvo el porcentaje de inhibición del crecimiento micelial del patógeno (Patil et al., 2014; Barari y Foroutan, 2016), al cual se le realizó el análisis de varianza y prueba de Tukey (SAS Institute, 2019).

\section{Ensayo II. Efecto in vitro de pesticidas químicos y botánicos sobre el hongo fitopatógeno}

En este ensayo se evaluaron en $20 \mathrm{~mL}^{-1}$ de PDA seis fungicidas químicos, tres compuestos botánicos y un testigo: T1: Testigo, T2: oxicloruro de cobre $0.06 \mathrm{~g}$ (Cupravit $\left.{ }^{\circledR}\right)$, T3: captan $0.044 \mathrm{~g}\left(\right.$ Captan $\left.^{\circledR}\right)$, T4: carbendazim $0.03 \mathrm{~g}$ (Bavistin $\left.{ }^{\circledast}\right)$, T5: mancozeb $0.05 \mathrm{~g}\left(\right.$ (Manzate $\left.^{\circledR}\right)$, T6: Ditiocarbamato de zinc $0.05 \mathrm{~g}$ (Zineb $\left.{ }^{\circledR}\right)$, T7: benomilo 0.009 g (Promyl $\left.{ }^{\circledR}\right)$, T8: extracto de canela Cinnamomun zeylanicum $0.05 \mathrm{~mL}$ (Qanum ${ }^{\circledR}$ ), T9: extracto de ajo Allium canadense $0.01 \mathrm{~mL}$ (Edoca Allium ${ }^{\circledR}$ ), T10: extracto de neem Azadirachta indica $0.01 \mathrm{~mL}\left(\mathrm{Niimax}^{\circledR}\right)$.

Los 10 tratamientos se distribuyeron completamente al azar con cinco repeticiones. Cada una de las 50 unidades experimentales fue una caja Petri como la utilizada en el Ensayo I. Los productos químicos y orgánicos, adquiridos en el mercado de agroquímicos, se evaluaron con la técnica 
del medio de cultivo PDA envenenado (Kumar y Mane, 2017), por lo que se preparó el PDA repartido en tubos de ensayo (dosis: $20 \mathrm{~mL} /$ tubo). Posterior a la esterilización se dejó enfriar el medio $\left( \pm 40{ }^{\circ} \mathrm{C}\right)$ y los $20 \mathrm{~mL}$ de PDA se vaciaron sobre el producto vegetal o químico vertido antes en el fondo de la caja, la cual se agitó suavemente para homogenizar la mezcla. Después de solidificar a temperatura ambiente, en el centro de la caja se sembró un disco de PDA ( $\varnothing=5 \mathrm{~mm})$ con $F$. solani, de 11 días de edad, incubado antes en PDA. Las cajas se sellaron con cinta parafilm y se incubaron $\mathrm{a} \pm 28^{\circ} \mathrm{C}$ con fotoperiodo $12 / 12 \mathrm{~h}$. El diámetro de la colonia del hongo se midió diariamente durante 144 horas, con lo cual se obtuvo el porcentaje de inhibición del crecimiento micelial del patógeno. En este ensayo también se realizó el mismo análisis estadístico realizado en Ensayo I.

\section{RESULTADOS Y DISCUSIÓN}

\section{Identificación morfológica y molecular del agente causal de la pudrición radical y marchitez en jitomate}

Se identificó a Fusarium solani como responsable de la infección de raíz de jitomate. El aislamiento monospórico del hongo creció $0.05 \mathrm{~cm} \mathrm{dia}^{-1}$, desarrolló micelio septado, hialino, con crecimiento blanco algodonoso, que se tornó de color rosa pálido o morado suave al madurar. El hongo produjo microconidios hialinos, elipsoides y con una a dos células, macroconidios con tres a cinco células, que se adelgazaron gradualmente y se encorvaron hacia los extremos; las clamidosporas fueron marrones, globosas y usualmente solitarias. Las características morfológicas fueron similares a las descritas para Fusarium solani, por Watanabe (2010) y Leslie y Summerell (2006). Los productos obtenidos de la región intergénica interna ITS y del factor de elongación de la traducción (TEF-1a) presentaron fragmentos de 500 y 700 pares de bases, respectivamente, con los siguientes números de acceso KY923274.1 y KY923280.1. La comparación de estas secuencias a través del banco de datos de genes (NCBI) indicó que tuvieron 99 y 100\% de similitud con Fusarium solani.

\section{Prueba de patogenicidad}

Se comprobó que el aislamiento monospórico de Fusarium solani es patogénico, porque provocó síntomas de pudrición de raíz y marchitez en las plantas sanas de jitomate a los ocho días después de la inoculación. Las plantas utilizadas como testigo permanecieron sanas, mientras que en las inoculadas hubo reducción del crecimiento y amarillamiento del follaje. El hongo reaislado presentó la misma morfología que el aislamiento originalmente inoculado, con lo que se cumplieron los postulados de Koch (Agrios, 2005)

\section{Ensayo I. Efecto de metabolitos extracelulares de Trichoderma spp. sobre Fusarium solani}

En el diámetro de las colonias del hongo hubo diferencias altamente significativas $(P<0.0001)$ en todas las horas de medición de esta variable, con excepción de la evaluación realizada a las $24 \mathrm{~h}$. El hongo creció a una tasa promedio de $1.33 \mathrm{~cm} \mathrm{dia}{ }^{-1}$. En los tratamientos con los metabolitos producidos por Trichoderma sp. (nativa de Iguala) y T. virens G-41 se presentó el menor crecimiento de F. solani (Cuadro 1); el testigo presentó el mayor promedio del diámetro. Las dos cepas mencionadas provocaron el máximo porcentaje de inhibición, con 79.19 y $77.81 \%$, respectivamente. T. asperellum y $T$. harzianum inhibieron 39.06 y $49.37 \%$ el crecimiento de F. solani. En el testigo, el hongo tuvo $100 \%$ de crecimiento (Cuadro 1). Ommati y Zaker (2012) observaron que T. asperellum y T. harzianum inhiben el crecimiento de F. solani en 44.33 y $34.33 \%$, respectivamente. Por otro lado, Da Silva et al. (2014) observaron que $T$. asperellum y $T$. harzianum inhiben a $F$. solani entre 51.9 a $69.8 \%$ y 49.5 a $64.9 \%$, respectivamente, resultados superiores a los obtenidos en el presente estudio.

De acuerdo con Vargas-Hoyos et al. (2012), la antibiosis ejercida por Trichoderma spp. se debe a la producción de metabolitos tóxicos y antibióticos, como la gliotoxina, trichodermina, viridina, suzakacilina, alamectina, demadina, trichotecenos y trichorzianina, los cuales son responsables de inhibir el crecimiento de hongos patógenos. También, la inhibición del crecimiento de los hongos fitopatógenos por Trichoderma spp. se debe a que este biocontrolador se adapta pronto a condiciones de crecimiento in vitro y coloniza rápidamente el espacio (Vargas-Hoyos et al., 2012; Singh et al., 2014; Ruano-Rosa et al., 2014). Por otro lado, González et al. (2012) indican que la actividad enzimática quinolítica y glucanolítica de Trichoderma asperellum actúa contra un amplio rango de hongos y es efectiva para inhibir totalmente la germinación de esporas de Botrytis cinerea, Fusarium solani, Fusarium graminearum y Phytium sp.

\section{Ensayo II. Efecto de pesticidas químicos y botánicos contra Fusarium solani}

Se encontraron diferencias altamente significativas $(P<$ 0.0001 ) provocadas por efecto de los tratamientos sobre el crecimiento de las colonias de F. solani (Cuadro 2). Todos los tratamientos químicos tuvieron efecto fungicida, a excepción del zineb, que junto con los extractos orgánicos presentan actividad fungistática sobre el patógeno. En los tratamientos con los fungicidas químicos oxicloruro 
de cobre, captan, carbendazim, mancozeb y benomilo se obtuvo $100 \%$ de efectividad biológica en el control de $F$. solani, con zineb $33.8 \%$ y con los pesticidas botánicos de 30 a $43.8 \%$ (Cuadro 2).

En condiciones in vitro Fareed et al. (2015) evaluaron la efectividad de oxicloruro de cobre sobre $F$. oxysporum f. sp. cucumerinum, causante de la marchitez en pepino, y encontraron como mayor inhibición $49.65 \%$, porcentaje menor que el $100 \%$ obtenido en el presente estudio, con el mismo ingrediente activo probado contra F. solani. El efecto fungitóxico obtenido con este fungicida se debe a que los iones de cobre reaccionan con componentes de ciertos aminoácidos, provocando la desnaturalización de las proteínas y enzimas, lo que altera los sistemas de transporte de energía y la integridad de la membrana en la célula fungosa (FRAC, 2018). Asimismo, el benomilo fue utilizado por Amini y Sidovich (2010) en condiciones in vitro contra F. oxysporum f. sp. lycopersici y reportaron que este producto químico inhibió 94 y 100 \% al patógeno, respectivamente. Estos resultados son similares a los obtenidos en la presente investigación, en dondeel fungicida también suprimió 100 \% el crecimiento del hongo, quizá porque este compuesto benzimidazol penetra a la célula fúngica y reacciona con las proteínas formando quelatos y desalojando metales esenciales e hidrógeno (Pemán

Cuadro 1. Comparación de los valores promedios del diámetro $(\mathrm{cm})$ de las colonias y porcentaje de inhibición de $F$. solani en el Ensayo I.

\begin{tabular}{|c|c|c|c|c|c|c|c|c|c|c|c|c|c|c|}
\hline \multirow{3}{*}{$\begin{array}{l}\text { Tratamiento } \\
\text { Testigo }\end{array}$} & \multicolumn{12}{|c|}{ Periodo de incubación (horas) } & \multirow{2}{*}{\multicolumn{2}{|c|}{$\mathrm{Pl}^{+}(\%)$}} \\
\hline & \multicolumn{2}{|c|}{24} & \multicolumn{2}{|c|}{48} & \multicolumn{2}{|c|}{72} & \multicolumn{2}{|c|}{96} & \multicolumn{2}{|c|}{120} & \multicolumn{2}{|c|}{144} & & \\
\hline & 1.10 & $a^{ \pm}$ & 2.04 & a & 4.30 & a & 5.90 & a & 7.50 & a & 8.00 & a & 00.00 & c \\
\hline Trichoderma sp. & 0.95 & a & 1.10 & $b$ & 1.20 & $d$ & 1.50 & $d$ & 1.70 & c & 1.70 & c & 79.19 & a \\
\hline T. asperellum & 0.99 & a & 1.40 & a & 2.10 & $b$ & 2.70 & $b$ & 3.10 & b & 4.90 & $b$ & 39.06 & $b$ \\
\hline T. virens G-41 & 0.96 & a & 1.20 & $b$ & 1.30 & c & 1.50 & c & 1.70 & $d$ & 1.80 & c & 77.81 & a \\
\hline T. harzianum & 1.05 & a & 1.40 & a & 1.90 & $b$ & 2.70 & $b$ & 3.60 & b & 4.10 & $b$ & 49.37 & $b$ \\
\hline
\end{tabular}

产Medias con letras iguales por columnas no son estadísticamente diferentes (Tukey, 0.05). ${ }^{\dagger} \mathrm{PI}$ : porcentaje de inhibición.

Cuadro 2. Comparación de los valores promedios del diámetro $(\mathrm{cm})$ de las colonias y porcentaje de inhibición de $F$. solani en el Ensayo II.

\begin{tabular}{|c|c|c|c|c|c|c|c|c|c|c|c|c|c|c|}
\hline \multirow{3}{*}{$\begin{array}{l}\text { Tratamiento } \\
\mathrm{T} 1\end{array}$} & \multicolumn{12}{|c|}{ Periodo de incubación (horas) } & \multirow{2}{*}{\multicolumn{2}{|c|}{$\mathrm{Pl}^{+}(\%)$}} \\
\hline & \multicolumn{2}{|c|}{24} & \multicolumn{2}{|c|}{48} & \multicolumn{2}{|c|}{72} & \multicolumn{2}{|c|}{96} & \multicolumn{2}{|c|}{120} & \multicolumn{2}{|c|}{144} & & \\
\hline & 0.8 & $a^{ \pm}$ & 2.4 & a & 4.0 & a & 5.7 & a & 7.1 & a & 8.0 & a & 0.0 & c \\
\hline T2 & 0.0 & $b$ & 0.0 & c & 0.0 & c & 0.0 & c & 0.0 & C & 0.0 & c & 100.0 & a \\
\hline T3 & 0.0 & $b$ & 0.0 & c & 0.0 & c & 0.0 & c & 0.0 & c & 0.0 & c & 100.0 & a \\
\hline T4 & 0.0 & $b$ & 0.0 & c & 0.0 & c & 0.0 & c & 0.0 & c & 0.0 & c & 100.0 & a \\
\hline T5 & 0.0 & $b$ & 0.0 & c & 0.0 & c & 0.0 & c & 0.0 & c & 0.0 & c & 100.0 & a \\
\hline T6 & 0.8 & $a b$ & 1.6 & $b$ & 2.4 & $b$ & 3.4 & $b$ & 4.1 & b & 5.3 & $a b$ & 33.8 & b \\
\hline T7 & 0.0 & $b$ & 0.0 & c & 0.0 & c & 0.0 & c & 0.0 & c & 0.0 & C & 100.0 & a \\
\hline T8 & 0.8 & a & 1.2 & $b$ & 2.4 & $b$ & 3.2 & $b$ & 4.0 & $b$ & 4.5 & $b$ & 43.4 & $b$ \\
\hline T9 & 0.8 & a & 1.7 & $b$ & 2.3 & $b$ & 3.3 & $b$ & 4.6 & $a b$ & 5.6 & $a b$ & 30.0 & $b$ \\
\hline T10 & 0.8 & a & 1.4 & $\mathrm{~b}$ & 2.2 & b & 2.7 & $b$ & 3.6 & $b$ & 4.5 & $b$ & 43.8 & $b$ \\
\hline
\end{tabular}

T1: testigo, T2: oxicloruro de cobre $0.06 \mathrm{~g}$ (Cupravit $\left.{ }^{\circledR}\right)$, T3: captan 0.044 g (Captan $\left.{ }^{\circledR}\right)$, T4: carbendazim $0.03 \mathrm{~g}\left(\right.$ Bavistin $\left.^{\circledR}\right)$, T5: mancozeb $0.05 \mathrm{~g}$ $\left(\right.$ Manzate $\left.^{\circledR}\right)$, T6: ditiocarbamato de zinc $0.05 \mathrm{~g}$ (Zineb $\left.{ }^{\circledR}\right)$, T7: benomilo $0.009 \mathrm{~g}$ (Promyl $\left.{ }^{\circledR}\right)$, T8: extracto de canela Cinnamomun zeylanicum 0.05 $\mathrm{mL}\left(\right.$ Qanum $\left.^{\circledR}\right)$, T9: extracto de ajo Allium canadense $0.01 \mathrm{~mL}$ (Edoca Allium $\left.{ }^{\circledR}\right)$, T10: extracto de neem Azadirachta indica $0.01 \mathrm{~mL}\left(\right.$ Niimax $\left.^{\circledR}\right)$, ${ }^{\dagger} \mathrm{Pl}$ : Porcentaje de inhibición. ${ }^{ \pm}$Medias con letras iguales por columnas no son estadísticamente diferentes (Tukey, 0.05). 
et al., 2009). En otra investigación, Da Silva et al. (2014) estudiaron in vitro el efecto del mancozeb sobre F. solani y reportaron que este pesticida inhibió $42.5 \%$ el crecimiento del micelio del patógeno, valor inferior al $100 \%$ obtenido en el presente trabajo con el mismo tratamiento. De acuerdo con la FRAC (2018), el mancozeb tiene un modo de acción multisitio, por lo que es de amplio espectro y protector; actúa formando compuestos que se unen con grupos sulfhidrilo de aminoácidos y provoca desnaturalización de las proteínas y enzimas y, consecuentemente, suprime el crecimiento del patógeno. El captan es fungitóxico, debido a que afecta el transporte de energía en las mitocondrias y el funcionamiento fisiológico de las membranas en las células fungosas y obstruye la actividad de las enzimas sulfhídricas, con lo que ocurre liberación de tiofosgeno que mata al patógeno (FRAC, 2018). Türkkan y Erper (2015) observaron que en condiciones in vitro el captan inhibió $100 \%$ a Fusarium spp., resultado similar al promedio de $100 \%$ obtenido con este tratamiento en el presente experimento. Bolívar et al. (2009) evaluaron la antibiosis ejercida por diferentes compuestos botánicos contra Colletotrichum gloeosporioides y encontraron porcentajes de inhibición entre 19.9 y $37.1 \%$, inferiores a los obtenidos en la presente investigación. Por su parte, Joseph et al. (2008) reportan al extracto de neem como un tratamiento efectivo y recomendado como preventivo para el manejo de la marchitez de la berenjena causada por F. solani.

\section{CONCLUSIONES}

La especie Fusarium solani fue identificada como agente causal de pudrición radical y marchitez del jitomate. El cultivo puro de Fusarium fue patogénico cuando se inoculó en raíces de plantas jóvenes de jitomate. Las especies Trichoderma sp., Trichoderma asperellum, Trichoderma virens G-41 y Trichoderma harzianum presentaron efecto fungistático sobre Fusarium. Los productos químicos oxicloruro de cobre, captan, carbendazim, mancozeb y benomilo tuvieron acción fungicida contra el hongo fitopatógeno y el ditiocarbamato de zinc fue fungistático. Los extractos de canela, ajo y neem actuaron como fungistáticos contra Fusarium.

\section{BIBLIOGRAFÍA}

Agrios G. N. (2005) Plant Pathology. 5th Edition. Elsevier Academic Press. Burlington, Ma. USA. $952 \mathrm{p}$.

Ahmad W., S. Shilpa and K. Sanjay (2017) Phytochemical Screening and antimicrobial study of Euphorbia hirta extracts. Journal of Medicinal Plants Studies 5:183-186.

Amini J. and D. Sidovich (2010) The effects of fungicides on Fusarium oxysporum f. sp. lycopersici associated with Fusarium wilt of tomato. Journal of Plant Protection Research 50:172-178, https://doi.org/10.2478/v10045-010-0029-x

Andrade-Hoyos P., H. V. Silva-Rojas and O. Romero-Arenas (2020) Endophytic Trichoderma species isolated from Persea americana and Cinnamomum verum roots reduce symptoms caused by
Phytophthora cinnamomi in avocado. Plants 9:1220, https:// doi.org/10.3390/plants9091220

Barari H. and A. Foroutan (2016) Biocontrol of soybean charcoal root rot disease by using Trichoderma spp. Cercetări Agronomice în Moldova XLIX:41-51, doi: 10.1515/cerce-2016-0014

Bhowmik D., K. P. S. Kumar, S. Paswan and S. Srivastava (2012) Tomato a natural medicine and its health benefits. Journal of Pharmacognosy and Phytochemistry 1:33-43.

Dan W., J. Gao, L. Li, Y. Xu, J. Wang and J. Dai (2021) Cellular and nontarget metabolomics approaches to understand the antifungal activity of methylaervine against Fusarium solani. Bioorganic \& Medicinal Chemistry Letters 43:128068, https://doi. org/10.1016/j.bmcl.2021.128068

Damalas C. A. (2016) Safe food production with minimum and judicious use of pesticides. In: Food Safety. J. Selamat and S. Z. Iqbal (eds.). Springer, https://doi.org/10.1007/978-3-319-392530_3

Da Silva A. N., G. B. de Azevedo, G. G. R. Sobrinho y Q. S. de Novaes (2014) Efecto de los productos químicos y de Trichoderma spp. en el control del Fusarium solani de la fruta de pasión. Interciencia 39:398-403, https://www.redalyc.org/pdf/339/33931213007. pdf

Fareed G., M. Atiq, M. U. Manzar-Abbas, G. Abbas and K. Hayat (2015) In vitro and in vivo management of Fusarium wilt of cucumber (FWC) through various chemicals. Advances in Zoology and Botany 3:169-174, http://dx.doi.org/10.13189/azb.2015.030401

Fiedor J. and K. Burda (2014) Potential role of carotenoids as antioxidants in human health and disease. Nutrients 6:466-488, https://doi. org/10.3390/nu6020466

FRAC, Fungicide Resistance Action Committee (2018) FRAC Code List: Fungicides sorted by mode of action (including FRAC Code numbering), http://www.phi-base.org/images/fracCodeList. pdf/ (Agosto 2021).

González I., D. Infante, B. Martínez, Y. Arias, N. González, L. Miranda y B. Peteira (2012) Inducción de quitinasas y glucanasas en cepas de Trichoderma spp. promisorias como agentes para el control biológico. Biotecnología Aplicada 29:1216, http://scielo.sld.cu/scielo.php?script=sci_arttext\&pid $=$ S1027-28522012000100002

Joseph B., M. Ahmad Dar and V. Kumar (2008) Bioefficacy of plant extracts to control Fusarium solani f. sp. melongenae incitant of brinjal wilt. Global Journal of Biotechnology \& Biochemistry 3:56-59, https://pdfs.semanticscholar.org/5247/08e77d3e1bcfd0ad49 a5acf090d7fd97ba71.pdf

Hoda M. S., G. M. Abdel-Fattah and E. A. Metwally (2016) Antagonistic interactions between the foliar pathogen Botrytis fabae Sard. and Trichoderma harzianum Rifai. Asian Journal of Plant Pathology 10:21-28, https://scialert.net/abstract/?doi=ajppaj.2016.21.28

Hsuan H. M., S. Baharuddin and Z. Latiffah (2011) Molecular identification of Fusarium species in Gibberella fujikuroi species complex from rice, sugarcane and maize from Peninsular Malaysia. Int $\mathrm{J}$ Mol Sci. 12:6722-32, https://doi: 10.3390/ijms12106722

Keyworth W. G. (1951) A Petri-dish moist chamber. Transactions of the British Mycological Society 34: 291-292, https://doi. org/10.1016/S0007-1536(51)80054-8

Kumar P. and S. S. Mane (2017) Studies on the Compatibility of biocontrol agents with certain fungicides. International Journal of Current Microbiology and Applied Sciences 6:1639-1644, http://dx.doi. org/10.20546/ijcmas.2017.603.189

Lengai G. M. W., J. W. Muthomi and E. R. Mbega (2020) Phytochemical activity and role of botanical pesticides in pest management for sustainable agricultural crop production. Scientific African 7, e00239, https://doi.org/10.1016/j.sciaf.2019.e00239

Leslie J. F. and B. A. Summerell (2006) The Fusarium Laboratory Manual. Blackwell Publishing, Hoboken, 1-2, https://doi. org/10.1002/9780470278376

Malandrakis A., E. R. Daskalaki, V. Skiada, K. K. Papadopoulou and N. Kavroulakis (2018) A Fusarium solani endophyte vs fungicides: Compatibility in a Fusarium oxysporum f. sp. radicislycopersicitomato pathosystem. Fungal Biology 122:1215-1221, https:// doi.org/10.1016/j.funbio.2018.10.003

Michel-Aceves A. C., J. Hernández-Morales, R. Toledo-Aguilar, J. E. S. López y T. Romero-Rosales (2019) Capacidad antagónica de 
Trichoderma spp. nativa contra Phytophthora parasitica y Fusarium oxysporum aislados de cultivos de jamaica. Revista Fitotecnia Mexicana 42:235-241, https://doi.org/10.35196/ rfm.2019.3.235-241

Morales M. L., P. Andrade-Hoyos, M. A. Valencia-de Ita, O. Romero-Arenas, H. V. Silva-Rojas y C. A. Contreras-Paredes (2020) Caracterización de hongos asociados al cultivo de fresa y efecto antagonista in vitro de Trichoderma harzianum. Revista Mexicana de Fitopatología 38: 434-449, http://dx.doi.org/10.18781/R.MEX. FIT.2005-7

Nagendran K., M. Loganathan, S. Saha, A. Mishra, K. K. Pandey, R. M. Rai, S. ... and B. Singh (2016) Biological management of wilt disease on chilli caused by Fusarium solani. Vegetable Science 43:253256, https://www.indianjournals.com/ijor.aspx?target=ijor:vgt\& volume $=43 \&$ issue $=2 \&$ article $=019$

Naranjo R. D. D. P., S. Otaiza, A. C. Saragusti, V. Baroni, A. D. V. Carranza, I. E. Peralta, E. M. Valle, F. Carrari and R. Asis (2016) Hydrophilic antioxidants from Andean tomato landraces assessed by their bioactivities in vitro and in vivo. Food Chemistry 206:146-155, https://doi.org/10.1016/j.foodchem.2016.03.027

Ommati F. and M. Zaker (2012) In vitro and greenhouse evaluations of Trichoderma isolates for biological control of potato wilt disease (Fusarium solani). Archives of Phytopathology and Plant Protection 45:1715-1723, https://doi.org/10.1080/0323 5408.2012.702467

Osuna-Canizalez F. D. J., M. F. Moreno-López, F. García-Pérez, S. RamírezRojas y J. Canul-Ku (2012) Biocontrol de la pudrición de raíz de nochebuena de interior con Trichoderma spp. Revista Mexicana de Ciencias Agrícolas 3:553-564, http://www.scielo. org.mx/pdf/remexca/v3n3/v3n3a11.pdf

Patil N. N., M. S. de Waghmo, P. S. Gaikwad, M. H. Gajbhiye, A. B. Gunjal, N. Nawani and B. P. Kapadnis (2014) Potential of Microbispora sp. V2 as biocontrol agent against Sclerotium rolfsii, the causative agent of southern blight of Zea mays L. (Baby corn) in vitro studies. Indian Journal of Experimental Biology 52:1147-1151, http://nopr.niscair.res.in/handle/123456789/29757

Pemán J., E. Cantón and A. Espinel-Ingroff (2009) Antifungal drug resistance mechanisms. Expert Review of Anti-infective Therapy 7:453-460, https://doi.org/10.1586/eri.09.18

Portal N., A. Soler, P. A. M. Alphonsine, O. BorrasHidalgo, R. Portieles, L. M. PeñaRodriguez and J. D. Walton (2018) Nonspecific toxins as components of a host specific culture filtrate from Fusarium oxysporum f. sp. cubense race 1. Plant Pathology 67:467-476, https://doi.org/10.1111/ppa.12736

Rashid T. S., S. A. Qadir and H. K. Awla (2021) Induction of defence related enzymes and biocontrol efficacy of Trichoderma harzianum in tomato plants infected with Fusarium oxysporum and Fusarium solani. Acta Agriculturae Slovenica 11: 1-6, doi:10.14720/aas.2021.117.1.16220riginal research article / izvirni znanstveni članek
Renna M., M. Durante, M. Gonnella, D. Buttaro, M. D'Imperio, G. Mita and F. Serio (2018) Quality and nutritional evaluation of Regina tomato, a traditional long-storage Landrace of Puglia (Southern Italy). Agriculture 83:1-15, https://doi.org/10.3390/ agriculture8060083

Romero-Rosales T., J. Acuña-Soto, A. Azuara-Domínguez, M. O. Lázaro-Dzul, A. Monteon-Ojeda, H. Vargas-Madriz y Y. Secundino-Eusebio (2021) Identificación y evaluación antagónica in vitro de cepas nativas de Trichoderma spp. sobre hongos fitopatógenos asociados al manchado del cáliz en jamaica (Hibiscus sabdariffa L.) Tropical and Subtropical Agroecosystems 24: 1-10, https:// www.researchgate.net/publication/347983409

Ruano-Rosa D., F. M. Cazorla, N. Bonilla, R. Martín-Pérez, A. De Vicente and C. López-Herrera (2014) Biological control of avocado white root rot with combined applications of Trichoderma spp. and rhizobacteria. European Journal of Plant Pathology 138:751762, https://doi.org/10.1007/s10658-013-0347-8

SAS Institute Inc. (2019) SAS user's guide: Statistics. Relase 6.04. Ed. SAS Institute incorporation, Cary, NC. USA.

Singh R. K., P. Kumar, N. N. Tiwari, S. P. Singh, A. K. Tiwari, S. K. Vishwakarma and A. Kumar (2014) Role of endochitinase gene and efficacy of Trichoderma against Colletotrichum falcatum Went. causing red rot disease in sugarcane. Sugar Tech 16:180-188, https:// doi.org/10.1007/s12355-013-0254-5

Silva R. N., V. N. Monteiro, A. S. Steindorff, E. V. Gomes, E. F. Noronha and C J. Ulhoa (2019) Trichoderma/pathogen/plant interaction in preharvest food security. Fungal Biology 123:565-583, https://doi. org/10.1016/j.funbio.2019.06.010

Türkkan M. and i. Erper (2015) Inhibitory influence of organic and inorganic sodium salts and synthetic fungicides against bean root rot pathogens. Gesunde Pflanzen 67:83-94, https://doi. org/10.1007/s10343-015-0339-z

Vargas-Hoyos H. A., E. A. Rueda-Lorza y E. Gilchrist-Ramelli (2012) Actividad antagónica de Trichoderma asperellum (Fungi: Ascomycota) a diferentes temperaturas. Actualidades Biológicas 34:103-112, http://www.scielo.org.co/pdf/acbi/v34n96/v34n96a08.pdf

Varma S. and D. Saran (2019) Application of botanicals: An eco-friendly approach for plant disease management. Agriculture \& Food: e- Newsletter 1: 343-345, www.agrifoodmagazine.co.in

Watanabe T. (2010) Pictorial atlas of soil and seed fungi: Morphologies of cultured fungi and key to species. CRC Press. Florida, USA. $426 p$

White T. J., T. Bruns, S. Lee and J. Taylor (1990) Amplification and direct sequencing of fungal ribosomal RNA genes for phylogenies. In: PCR Protocols. M.A. Inns, D.H. Gelfland, J. J. Sninsky, and T.J. White (eds.). Academic Press. San Diego, CA. USA. pp: 315- 322

Zaker M. (2016) Natural plant products as eco-friendly fungicides for plant diseases control-a review. Agriculturists 14: 134-141, https://doi.org/10.3329/agric.v14i1.29111 
